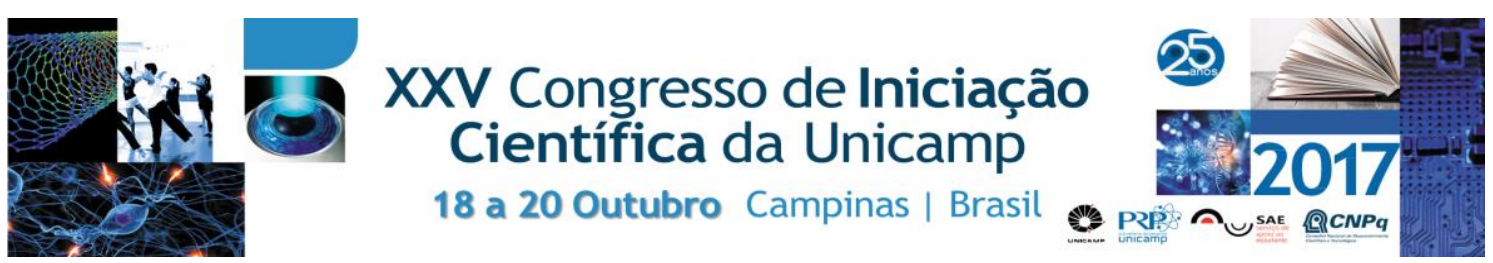

\title{
Dimorfismo sexual pelas vértebras Atlas de brasileiros
}

\author{
Larissa Padovan*, Graciele D. N. Silva, Maria Júlia A. Vicentin, Lucas Del Vigna P. Peixoto, Viviane Ulbricht; Cristhiane \\ Martins Schmidt; Eduardo Daruge Jr.; Francisco C. Groppo; Luiz Francesquini Júnior.
}

\section{Resumo}

Objetivo: Estabelecer o dimorfismo sexual através de medidas da vértebra Atlas. Metodologia: Estudo observacional analítico em 191 ossadas existentes no laboratório de antropologia física forense. Resultados: Verificou-se que as medidas são dimórficas e existe correlação moderada a boa entre as medidas dos diâmetros anteroposterior da vértebra e anteroposterior do canal raquidiano e também com o transverso máximo. O mesmo ocorre na relação entre as medidas anteroposterior do canal raquidiano e transverso do canal raquidiano. Foi possivel construir um logito [Sexo $=-$ $23.7+(0.18 \times$ Antero posterior da vértebra $)-(0.08 \times$ transverso do canal raquidiano $)+(0.25 \times$ transverso máximo $)]$ este permitiu um grau de acerto de $82,2 \%$. Conclusão: Concluiu-se ser possível o uso da vertebra Atlas na determinação do sexo como método auxiliar de identificação humana.

\section{Palavras-chave:}

Antropometria, Dimorfismo Sexual, Modelos Matemáticos

\section{Introdução}

A identificação é o processo de definição dos caracteres da identidade que pode ser feito ante mortem ou post mortem. A identificação humana post mortem é uma das grandes áreas de estudo e pesquisa da Odontologia e Medicina Legais. Este processo pode ser classificado em geral e individual. $O$ estudo geral trata dos aspectos que irão formar o biótipo do indivíduo, como determinação do sexo, estimativa da idade e da estatura e determinação da ancestralidade. Já na identificação individual há necessidade da presença de elementos comparativos anteriores à morte, que servem para estabelecer coincidências suficientes, sem a presença de aspectos discrepantes na identificação. Para os brasileiros, a determinação do sexo é o principal estudo antropométrico e tem suma importância em situações de desastres de grandes proporções, carbonizações, etc. Essa permite dividir e separar ossadas masculinas de ossadas femininas, o que diminui o contingente de busca, além de acelerar todo o processo de identificação. $O$ estudo da vértebra atlas é importante auxiliar no processo de identificação humana.

\section{Resultados e Discussão}

Foram medidas 191 vértebras atlas existentes no Laboratório de de antropologia física forense da FOP/UNICAMP, sendo 110 (57,6\%) masculinas e 81 $(42,4 \%)$ femininas, atuais e provenientes da região Sudeste do Brasil. Após aprovação no CEP (138/2014), foram feitas quatro medidas lineares. Tais medidas foram realizadas por meio do uso de paquímetro digital. A primeira parte do projeto foi o teste de calibração inter e intra examinador. De uma forma geral, uma taxa de concordância aceitável ficou na faixa $95 \%$. Após o teste de calibração ter sido feito com excelência, foram realizadas as mensurações necessárias e enviadas para o estatístico Prof. Dr. Francisco Carlos Groppo.

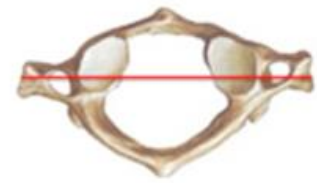

Diâmetro transverso máximo da vértebra

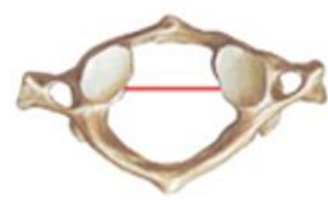

Diâmetro transverso do canal raquidiano

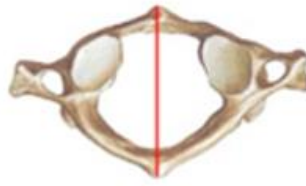

Diâmetro anteroposterior da vértebra

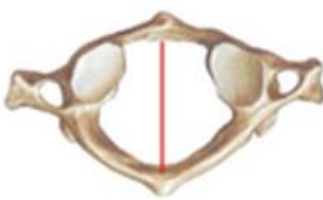

Diâmetro anteroposterior do canal raquidiano

\section{Conclusão}

Todas as medidas realizadas são dimórficas; foi possível construir um modelo matemático para a determinação do sexo logito [Sexo $=-\mathbf{2 3 . 7}+(0.18 \times$ Antero posterior da vértebra) $-(0.08 \times$ transverso este do canal raquidiano $)+(0.25 \times$ transverso máximo $)$; e este obteve $82,2 \%$ de acerto, se mostrando, portanto, eficaz na predição do sexo de ossadas de brasileiros.

Agradecimentos

Agradecimento a bolsa PIBIC/CNPq/SAE-PRP e a FOP/UNICAMP.

Manual de procedimentos em odontologia para identificação de vítimas de desastres, 2014.

Terada A.S.S.D. Identificação humana de vítimas de desastres de massa. http://revodonto.bvsalud.org?scielo.php?pid=S1413-

40122013000200018\&script=sci_arttext\&tlng $=\mathrm{p}$

Kanchan T. Métodos de escolhas em suicídios: diferenças de gênero e revisão daliteratura.https://scholar.gloogle.com.br/citations?view_op=view_citation\&hl $=\mathrm{ptBR} \&$ user $=\mathrm{h} 7 \mathrm{~d} 70 \mathrm{moAAAAJ} \&$ citation_for_view $=\mathrm{h} 7 \mathrm{~d} 70 \mathrm{moAAAAJ}: \mathrm{KUbvn}$ 5 osdkgC 